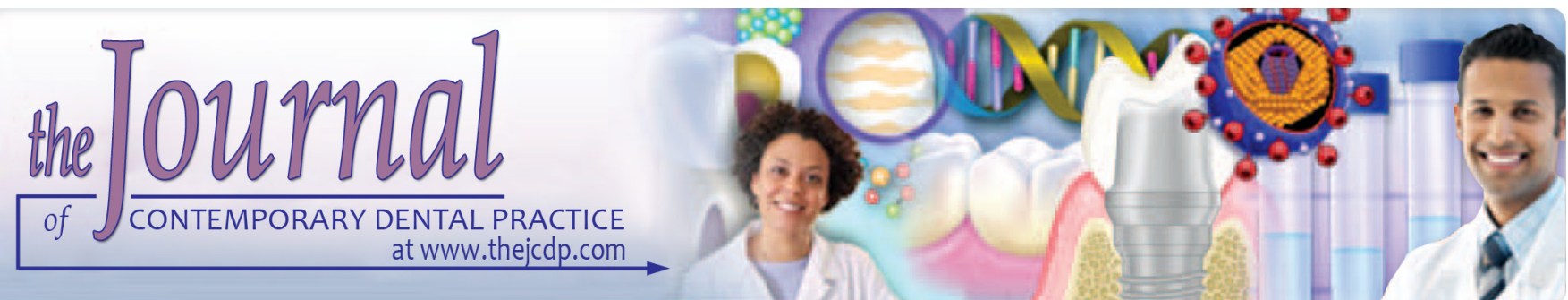

\title{
Fluoride, Thyroid Hormone Derangements and its Correlation with Tooth Eruption Pattern Among the Pediatric Population from Endemic and Non-endemic Fluorosis Areas
}

\author{
${ }^{1}$ Vaibhav Kumar, ${ }^{2}$ Puneet Chahar, ${ }^{3}$ Shweta Kajjari, ${ }^{4}$ Faizia Rahman, ${ }^{5}$ Deepak K Bansal, ${ }^{6}$ Junaid MH Kapadia
}

\begin{abstract}
Aim: To comparatively evaluate the status of fluoride in the body with thyroid activity in the pediatric population of endemic fluorosis areas. The present study also attempted to elucidate whether any correlation exists between fluoride and thyroid hormone derangement with delayed tooth eruption

Materials and Methods: A total of 400 pediatric subjects were included in the present study. All the patients were divided into two broad groups; groups A and B. Group A included 200 subjects who belonged to the endemic fluorosis area while Group B included remaining 200 subjects, who belonged to the fluorosis non-endemic area. Group B subjects were taken as control. Group A subjects were further divided into two study groups as follows: Group A1: 100 Paediatric subjects with dental fluorosis, and Group A 2: A total of one hundred pediatric subjects without dental fluorosis. Dean's index of fluorosis was calculated in all the patients. Blood samples were collected and were sent to a laboratory for assessment of thyroid hormone levels. All the results were subjected to statistical analysis by Statistical Package for the Social Sciences (SPSS) software.
\end{abstract}

Results: Mean thyroid stimulating hormone (TSH), water fluoride levels, urine fluoride levels and serum fluoride levels of subjects in group 1 were found to be significantly higher than

\footnotetext{
${ }^{1}$ Department of Public Health Dentistry, Terna Dental College, Nerul, Navi Mumbai, Maharashtra, India

${ }^{2}$ Maulana Azad Institute of Dental Sciences, New Delhi, India

${ }^{3}$ Department of Pedodontics, Subbaiah Institute of Dental Sciences, Shimoga, Karnataka, India

${ }^{4}$ Faculty of Dental Science, Institute of Medical Science, Banaras Hindu University, Varanasi, Uttar Pradesh, India

${ }^{5}$ Deptt. of Pedodontics and Preventive Dentistry. JCD Dental College (Sirsa) Haryana, India

${ }^{6}$ Public Health Dentistry, Bhabha College of Dental Sciences, Bhopal, Madhya Pradesh, India

Corresponding Author: Faizia Rahman, Faculty of Dental Science, Institute of Medical Science, Banaras Hindu University, Varanasi, Uttar Pradesh, India, Phone: 9501544877, Email: drfaiziarahman@gmail.com
}

that of subjects of group 2. Delayed tooth eruption was absent in subjects of group B while it was present in 100 subjects of group $A$. Thyroid hormone level derangement was seen in 54 percent subjects of group B, while it was seen in $67.5 \%$ subjects of group A.

Conclusion: Positive correlation exists between fluorosis and thyroid functional activity. However; the tooth eruption pattern is independent up on the thyroid hormone derangement.

Clinical significance: Delayed tooth eruption and alteration in thyroid hormone levels can occur in subjects of the endemic fluoride areas. Therefore, adequate measures should be taken for controlling such adverse effects.

Keywords: Fluorosis, Thyroid hormones, Tooth Eruption.

How to cite this article: Kumar V, Chahar P, Kajjari S Rahman F, Bansal DK, Kapadia JMH. Fluoride, Thyroid Hormone Derangements and its Correlation with Tooth Eruption Pattern Among the Pediatric Population from Endemic and Non-endemic Fluorosis Areas. J Contemp Dent Pract, 2018;19(12):1513-1517.

Source of support: Nil

Conflict of interest: None

\section{INTRODUCTION}

In the past couple of decades, there has been a tremendous increase in the field of preventive dentistry concerning the use of fluorides. Fluorides have been a topic of extreme interest, ever since its discovery. ${ }^{1}$ In fighting the tooth decay process, fluorides have been extensively used in the field of dentistry. However; is often regarded as a "double-edged sword" as excessive consumption of fluoride also leads to a risk of cumulative intoxication resulting in minor physiological alteration. ${ }^{2}$

Rural areas of India consist of more than seventy percent of the total population. Centralized water supply faculty is not up to the mark in these areas. For drinking purposes, groundwater is the major source, on which population of these areas is dependent. ${ }^{3}$ 
As demonstrated by animal studies, impairment in the thyroid function occurs at higher concentrations of fluoride. In laboratory experiments, when animal subjects were administered with fluoride doses of three to six $\mathrm{mg} / \mathrm{kg}$ per day, a significant fall in the concentrations of triiodothyronine (T3) and thyroxine (T4), thyroid peroxidase and 3G-leucine were observed. Also, under the effect of low iodine intake, larger alterations in the functions of the thyroid gland were observed. However; the actual mechanism responsible for producing all these changes is still not clearly understood., ${ }^{4,5}$

Fluoride affects the tooth development in a dosedependent manner. The interaction between the fluoride ions and hydroxyapatite molecules dramatically affects the different stages of tooth development of other dental tissues (particularly enamel). ${ }^{6}$

Hence; under the light of data mentioned above, the current investigation was planned to comparatively evaluate the status of fluoride in the body with the free T4, T3 and TSH levels of pediatric population in areas with and without endemic fluorosis. The present study also aimed to elucidate whether any correlation exists between fluoride and thyroid hormone derangement with delayed tooth eruption.

\section{MATERIALS AND METHODS}

The present study was conducted in the department of dentistry by including 400 pediatric subjects of 8 to 15 years age of mixed dentition period. Ethical clearance was obtained from the ethical committee of the institution, and written consent was also obtained from the guardians/parents of all the pediatric subjects. All the patients were divided into two broad groups; groups A and B. Group A included 200 subjects who belonged to the endemic fluorosis area while Group B included the remaining 200 subjects, who belonged to the fluorosis non-endemic area. Group B subjects were taken as control. Group A subjects were further divided into two study groups as follows:

- Group A1: One-hundred Paediatric subjects with dental fluorosis, and

- Group A2: One-hundred Paediatric subjects without dental fluorosis

Further division of the subjects of group A1 was done into two groups with 50 subjects in each group. A total of fifty subjects were taken from locations with the level of water fluoride up to $2.7 \mathrm{ppm}$, and the remaining 50 subjects were taken from areas with a level of water fluoridation up to $5.2 \mathrm{ppm}$. A similar division of the subjects of group A2 into two groups was done, with 50 subjects in each group. In a control group (group B), those subjects belonging to the non-endemic area were taken in which, dental fluorosis was absent.

Subjects more than 15 years of age, or having history of the presence of any other form of dental staining, cancer/chronic disease and having thyroid-interfering medication were excluded from the study.

Complete dental history in all the subjects was obtained along with the assessment of Dean's index. ${ }^{7}$ Dean's classification scale classifies the dental fluorosis into six grades as follows:

- Score 0 : Normal enamel,

- Score 0.5 : Very mild fluorosis,

- Score 1 : Mild fluorosis,

- Score 2 : Moderate fluorosis,

- Score 3 : Severe Fluorosis

The ra te of dental fluorosis (DF) \% was used for assessing the prevalence of dental fluorosis. Collections of blood samples were done in the morning time by from the subjects by venipuncture into the tubes, followed by separation of the samples by centrifugation. Serum was separated with the purpose of assessment of thyroid function test and estimation of fluorine in the serum. This was followed by refrigeration of the samples at four-degree centigrade. For estimation of the grade of exposure to fluorine compounds absorbed, $\mathrm{u}$ rinary fluoride is regarded as an indicator. Evaluation of the fluoride ion level in the body fluids was done using manual titration method, and automatic analyzer and radiometer. ${ }^{8}$ Assessment of serum thyroid hormone levels were done using Immuno Chemiluminescence Microparticle Assay with Autoanalyzer. ${ }^{7}$ All the results were subjected to statistical analysis by SPSS software version 17.0. Chi-square test and Mann Whitney test were used for assessment of the level of significance. The p-value of less than 0.05 was taken as significant.

\section{RESULTS}

In the present study, assessment of a total of 400 subjects was done, which were divided into two study groups; Group A and Group B. Subjects of Group A were divided into two subgroups; Subgroup A1 and Subgroup A2. Mean water fluoride levels of subjects of subgroup A1, subgroup A2, and group B were $1.1 \mathrm{ppm}, 3.3 \mathrm{ppm}$, and $0.99 \mathrm{ppm}$ respectively (Table 1 ). The range of serum fluoride levels of subjects of subgroupA1, A2, and group B was 0.05 to $0.71 \mathrm{ppm}, 0.05$ to $0.71 \mathrm{ppm}$ and 0.03 to 0.10 ppm respectively. Mean free T3 levels of the subjects of the subgroup A1, A2, and group B were $2.9 \mathrm{pg} / \mathrm{mL}, 2.7 \mathrm{pg} /$ $\mathrm{mL}$ and $3.01 \mathrm{pg} / \mathrm{mL}$ respectively (Table 2). Delayed tooth eruption was absent in subjects of group B while it was present in 100 subjects of group A. Thyroid hormone level derangement was seen in $54 \%$ subjects of group B, while it was seen in 67.5 percent subjects of group A (Table 3). 
Fluoride, Thyroid Hormone IRT Tooth Eruption Pattern

Table 1: Fluoride level range in various study groups

Table 2: Range of thyroid hormones in different study groups

\begin{tabular}{llllllll}
\hline Group & $\begin{array}{l}\text { Water fluoride } \\
(p p m)\end{array}$ & $\begin{array}{l}\text { Urine fluoride } \\
(p p m)\end{array}$ & $\begin{array}{l}\text { Serum fluoride } \\
(p p m)\end{array}$ & Group & $\begin{array}{l}\text { Free } \\
\text { T3 pg/ml }\end{array}$ & $\begin{array}{l}\text { Free } \\
\text { T4 ng/dL }\end{array}$ & $\begin{array}{l}\text { TSH } \\
\mu l U / m\end{array}$ \\
\hline A1 & $1.5-5$ & $0.27-8.6$ & $0.05-0.71$ & A1 & $1.2-4.21$ & $0.96-1.82$ & $1.34-8.31$ \\
A2 & $1.8-5.8$ & $0.6-7.64$ & $0.05-0.71$ & A2 & $1.5-4.68$ & $0.7-1.5$ & $1.88-10.14$ \\
B & $0.94-1.08$ & $0.22-1.07$ & $0.03-0.10$ & B & $1.84-4.08$ & $0.79-1.53$ & $0.99-3.39$ \\
\hline
\end{tabular}

Table 3: Thyroid hormone and serum fluoride level derangement in paediatric subjects of various study groups

\begin{tabular}{lllll}
\hline Parameter & & Group A1 & Group A2 & Group B \\
\hline $\begin{array}{l}\text { Thyroid } \\
\text { hormone level } \\
\text { derangement }\end{array}$ & Number & 69 & 66 & 54 \\
$\begin{array}{l}\text { Deranged } \\
\text { fluoride levels }\end{array}$ & Number & 96 & 66 & 54 \\
$\begin{array}{l}\text { Subjects with } \\
\text { delayed eruption }\end{array}$ & Number & 49 & 100 & 50 \\
& Percentage & 49 & 51 & 0 \\
\hline
\end{tabular}

Table 5: Correlation of delayed tooth eruption with thyroid hormone and fluoride derangement

\begin{tabular}{lll}
\hline Parameter & $p$-value & $r$-value \\
\hline Thyroid hormone level derangement & 0.52 & 0.24 \\
Deranged fluoride levels & $0.02^{*}$ & 0.86 \\
\hline
\end{tabular}

*Significant

Mean free T3, mean free T4, mean TSH levels of the subjects of group 1 were $3.125 \mathrm{pg} / \mathrm{mL}, 1.282 \mathrm{ng} / \mathrm{mL}, 3.849$ $\mu \mathrm{IU} / \mathrm{m}, 2.877 \mathrm{ppm}, 2.982 \mathrm{ppm}$, and $0.195 \mathrm{ppm}$ respectively. Mean free T3, mean Free T4, mean TSH levels of the subjects of group 2 were $2.698 \mathrm{pg} / \mathrm{mL}, 1.193 \mathrm{ng} / \mathrm{mL}$, $2.588 \mu \mathrm{IU} / \mathrm{m}, 1.020 \mathrm{ppm}, 0.761 \mathrm{ppm}$, and $0.059 \mathrm{ppm}$ respectively (Table 4). Mean TSH, water fluoride levels, urine fluoride levels and serum fluoride levels of subjects of group 1 were found to be significantly higher than that of subjects of group 2 (p-value $<0.05)$. Sixty percent of the subjects of the subgroup A2 had three score of dean's fluorosis index as shown in Graph 1. A positive correlation was observed while assessing the association between the deranged fluoride levels and delayed tooth eruption (Table 5). However; the negative correlation was observed while assessing the correlation between the delayed tooth eruption and thyroid hormone level derangement.

\section{DISCUSSION}

In context to humans, fluoride has both a positive and negative effect. In the field of dentistry, topical and systemic fluorides are continuously used for prevention of dental caries. Especially in the developed countries, a great reduction in the incidence of dental caries has been seen under the effect of fluorides. Fluoride intake is mostly commenced through drinking water. The concentration of fluoride level in majority countries of the subcontinent including India is greater the World Health Organization (WHO) guidelines values. ${ }^{910}$ Correlation of alteration in thyroid functions and levels of fluoride
Table 4: Comparison of different parameters in between two study groups

\begin{tabular}{llll}
\hline Variable & Group A & Group B & $p$-value \\
\hline Mean Free T3 $(\mathrm{pg} / \mathrm{ml})$ & 3.125 & 2.698 & 0.26 \\
Mean Free T4 $(\mathrm{ng} / \mathrm{dL})$ & 1.282 & 1.193 & 0.41 \\
Mean TSH $(\mu \mathrm{lU} / \mathrm{m})$ & 3.849 & 2.588 & $0.02^{*}$ \\
Mean Water fluoride $(\mathrm{ppm})$ & 2.877 & 1.020 & $0.01^{*}$ \\
Mean Urine fluoride $(\mathrm{ppm})$ & 2.982 & 0.761 & $0.02^{*}$ \\
Mean Serum fluoride $(\mathrm{ppm})$ & 0.195 & 0.059 & $0.03^{*}$ \\
\hline
\end{tabular}

*Significant

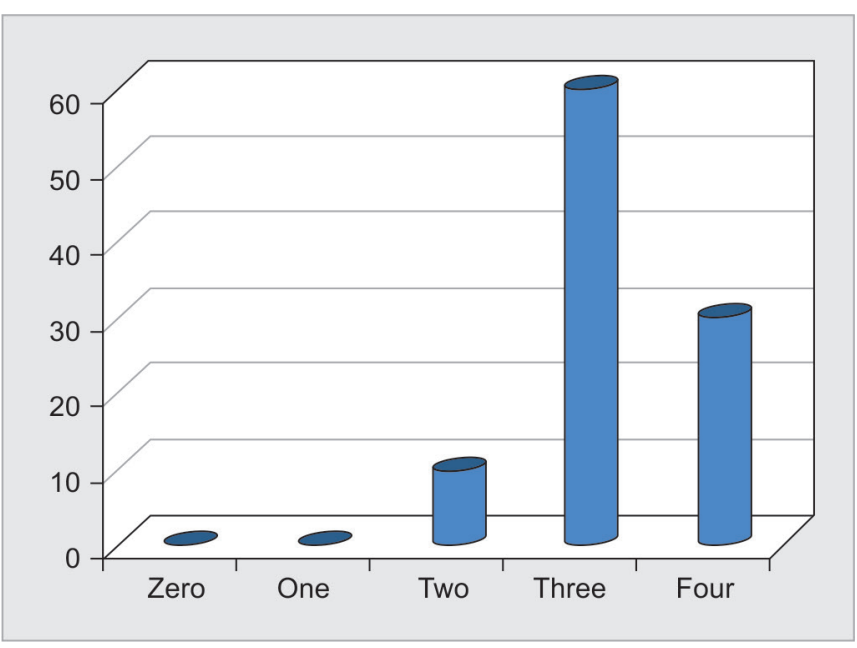

Graph 1: Subjects of Group A 1 with Dean's grades of fluorosis

intake is a topic of current research. Hence; under the light of data mentioned above, the ongoing investigation was planned to comparatively evaluate the status of fluoride in the body with the free T4, T3 and TSH levels of pediatric population in areas with and without endemic fluorosis.

In the present study, a positive correlation was obtained between water fluoride-urine fluoride and water fluorideserum fluoride levels. Our results were in concordance with the results obtained by Singh et al. and Rathee et al., who also observed similar findings in their study. ${ }^{6,11}$ In the present study, it was also observed that functional thyroid alterations were caused by high fluoride exposure, which was in correlation with the results obtained by Xiang et al. ${ }^{12}$ In a previous study conducted by Singh et al., authors comparatively evaluated the thyroid hormone levels and estimated fluoride status among pediatric subjects of age group of 8 to 15 years. Their study population comprised of two groups; endemic fluoride population, and nonendemic fluoride population. They concluded that it is desirable to test the fluoride content of the drinking water among with activity of thyroid hormones in pediatric 
subjects assessing the effect of deranged thyroid hormones on fluorosis. ${ }^{6}$

Hosur et al., in another study, assessed the impact of fluoride-induced thyroid alterations in subjects with dental fluorosis. A total of 65 subjects with dental fluorosis from endemic fluorosis areas were included in their study. Ten subjects with absence of dental fluorosis were taken as controls in their study. Assessment of fluoride levels of drinking water was done in their study. Along with this, they also assessed the levels of thyroid hormone levels in both the study groups. Among subjects with dental fluorosis, they didn't observe any significant alteration in the thyroid hormone levels. ${ }^{13}$ For the assessment of the severity of dental fluorosis, along with thyroid function and bone metabolic indicators among school children, Khandare et al. conducted a case-control study. They carried out the investigation in the area where drinking water was contaminated, and heat stressed. Study group in their research comprised of 824 subjects within the age group of 8 years to 15 years. In comparison to the subjects of the age-matched control group, the levels of dental fluorosis were significantly greater among children in the study group. Also in comparison to the controls, subjects of the study group had significantly higher urinary fluoride levels. Study groups subjects of their study had substantially lower nutritional status in comparison to the controls. In children of affected areas, thyroid functions were more significantly altered in comparison to the controls. From the results, they concluded that in comparison to the controls, children living in the fluoride endemic areas are more severely affected with altered thyroid and metabolic functions. ${ }^{14}$

Yun et al. investigated the current incidence of endemic fluorosis in the floodplain area. For carrying out the epidemiological survey of endemic fluorosis, they surveyed 16 countries. Assessment of fluoride level in the drinking water was done in both children and adults. From the results, they concluded that effective control of endemic fluorosis was still lacking in these areas, which suggested that there was still a need for preventive approaches. ${ }^{15}$ Growth disturbance often results from chronic over exposure in the individual with fluoride in drinking water. This occurs, particularly in adolescence. As stated by different authors, it results in thyroid dysfunction and disturbance in the development and eruption of dentition. 16,17 This was also evident in the current study, in which delayed eruption of teeth and altered thyroid function was seen in patients with fluoride endemic areas. However; we didn't observe any significant correlation between delayed tooth eruption and thyroid hormone derangement. Mixed findings have been reported in the past literature in relation to the association of fluoride exposure and thyroid functioning.
In few studies conducted in India and China, authors reported alteration of a minimum of one hormone among those deemed as having 'high' fluoride exposure. No significant differences among the levels of TSH in between fluoride endemic and non-endemic areas were reported by Michael et al. Lin et al. reported opposite findings in their study. They observed significant higher $\mathrm{TSH}$ activity in subjects of endemic fluoride areas in comparison to fluoride non-endemic areas. ${ }^{18-20}$

Although, the present study has not evaluated the derangement in fluoride and thyroid in males and females separately. Variation of serum thyroid hormone in males and females might influence tooth eruption pattern and fluorosis. However, past studies have shown contradicting results regarding the influence of gender on fluorosis and tooth eruption pattern which depend upon difference in geographic areas. ${ }^{21-23}$ However; further research is warranted in this field for a better understanding of the correlation between thyroid functional activity, tooth eruption changes, and fluorosis.

\section{CONCLUSION}

The present study validates the hypothesis that fluorosis and thyroid functional activity are positively correlated with each other. Excessive fluoride levels also lead to alteration in thyroid hormones activity. However; tooth eruption pattern is independent upon the thyroid hormone derangement but is affected by fluoride mineral. Therefore, we recommend that adequate measures should be taken for controlling the adverse effects of fluoride, especially in young and adolescent population.

\section{REFERENCES}

1. Shivaprakash PK, Ohri K, Noorani H. Relation between dental fluorosis and intelligence quotient in school children of Bagalkot district. J Indian Soc Pedod Prev Dent. 2011;29:117-120.

2. Brindha K, Elango L. Fluoride in groundwater: Causes, implications and mitigation measures. In: Monroy SD, editor. Fluoride Properties, Applications, and Environmental Management. 1st ed. New York: Nova Publishers; 2011. p111-136.

3. Mullenix PJ. Fluoride poisoning: A puzzle with hidden pieces. Int J Occup Environ Health. 2005;11:404-414.

4. National Research Council. Fluoride in drinking water: a scientific review of EPA's standards. Washington DC, USA: The National Academies Press, 2006.

5. 1Michael M, Barot VV, Chinoy NJ. Investigations of soft tissue functions in fluorotic individuals of North Gujarat. Fluoride 1996;29:63-71.

6. Singh N, Verma KG, Verma P, Sidhu GK, Sachdeva S. A comparative study of fluoride ingestion levels, serum thyroid hormone and TSH level derangements, dental fluorosis status among school children from endemic and non-endemic fluorosis areas. SpringerPlus. 2014;3:7. 
7. Kumar JV, Swango PA, Opima PN, Green EL. Dean's fluorosis index: an assessment of examiner reliability. J Public Health Dent. 2000 Winter;60(1):57-59.

8. Hall LL, Smith F, Lopez OH, Gardner DH. Direct potentiometeric determination of ionic fluoride in biological fluids. Clin Chem. 1972;18:1455-1458.

9. Saxena S, Sahay A, Goel P. Effect of fluoride exposure on the intelligence of school children in Madhya Pradesh, India. J Neurosci Rural Pract. 2012;3:144-149.

10. Everett ET. Fluoride's Effects on the Formation of Teeth and Bones, and the Influence of Genetics. J Dent Res. 2011;90:552-560.

11. Rathee N, Garg P, Pundir CS. Correlative study of fluoride content in urine, serum and urinary calculi. Indian J Clin Biochem. 2004;19:100-102.

12. Xiang Q, Chen L, Liang Y, Wu M, Chen B. Fluoride and thyroid function in children in two villages in China. J Toxicol Environ Health Sci. 2009;1:54-59.

13. Hosur MB1, Puranik RS, Vanaki S, Puranik SR. Study of thyroid hormones free triiodothyronine (FT3), free thyroxine (FT4) and thyroid stimulating hormone (TSH) in subjects with dental fluorosis. Eur J Dent. 2012 Apr;6(2):184-190.

14. Khandare AL1, GourineniSR2, Validandi V2. Dental fluorosis, nutritional status, kidney damage, and thyroid function along with bone metabolic indicators in school-going children living in fluoride-affected hilly areas of Doda district, Jammu and Kashmir, India. Environ Monit Assess. 2017 Oct 23;189(11):579.

15. Yun ZJ1, Chen PZ, Bian JC, Wang YT, Gao J, Ma AH, Liu Y, Li HX. Epidemiological investigation on endemic fluorosis along the Yellow River alluvial plain of Shandong province.
Zhonghua Liu Xing Bing Xue Za Zhi. 2010 Nov;31(11): 1280-1283.

16. Villa A, Anabalon M, Zohouri V, Maguire A, Franco AM, Rugg-Gunn A. Relationships between fluoride intake, urinary fluoride excretion and fluoride retention in children and adults: an analysis of available data. Caries Res. 2010;44:60-68.

17. Smith TM, Tafforeau P. New visions of dental tissue research: tooth development, chemistry, and structure. Evolutionary Anthro. 2008;17:213-226.

18. Michael M, Barot VV, Chinoy NJ. Investigations of soft tissue functions in fluorotic individuals of North Gujarat. Fluoride 1996;29:63-71.

19. Susheela AK, Bhatnagar M, Vig K. Excess fluoride ingestion and thyroid hormone derangements in children living in Delhi. India Fluoride 2005;38:98-108.

20. Lin FF, Aihaiti HX, Zhao J. The relationship of a low iodine and high-fluoride environment to subclinical cretinism in Xinjiang. IDD Newsletter 1991;7:24-25.

21. Bardal PAP, Olympio KPK, Buzalaf MAR, Bastos JRM . Dental caries and dental fluorosis in 7-12 years-old school children in Catalão, Goiás, Brasil. J Appl Oral Sci 2005;13: 35-40.

22. Mendonça LL, Kirchner UL, Costa RN, Giovannini JFBG, Pinto MR, Luz MAR. Estudo multicentro de fluorose dental e da cárie dental em escolares de 7 e 10 anos de Belo Horizonte. RPG 1998;5:101-109.

23. Michel-Crosato E, Biazevic MGH, Crosato E. Relationship between dental fluorosis and quality of life: a population based study. Braz Oral Res 2005;19:150-155. 